\title{
ĐÁNH GIÁ NĂNG LỰC SÁNG TẠO DOANH NGHIẸP
}

\author{
Võ Văn Quang
}

http://vovanquang.com/danh-gia-nang-luc-sang-tao-doanh-nghiep/

Ngày 27 tháng 04 năm 2014 


\section{ĐÁNH GIÁ NĂNG LỰC SÁNG TAQO DOANH NGHIỆP}

Hệ thống i2-Metrix của Boise State University (Mỹ) đã được ứng dụng tại Việt Nam cho cộng đồng doanh nghiệp Hàng Việt Nam Chất lượng cao bởi công ty DHVP Research \& Consultancy. Đánh giá Năng lực Sáng tạo (Creative \& Innovative Audit) là lĩnh vực cao của Creativity và Marketing Innovation. Chuyên gia xin trân trọng giới thiệu nội dung chương trình Đánh giá Năng lực Sáng tạo của DHVP trên trang VietBuzz sau đây...

$$
\text { 13482787573_4af0b7773c_o }
$$

\section{Sơ đồ mạng nhện của đánh giá lượng hoá năng lực sáng tạo theo 10 tiêu chí do giáo sư Nancy K. Napier (Boise University, Mỹ)}

(VietBuzz) - i2Metrix - bộ chỉ tiêu đo lường năng lực đổi mới sáng tạo (ĐMST) doanh nghiệp do BSA và DHVP Research phát triển - được thực hiện trong hai tháng đầu năm 2014 với 19 thành viên của CLB Doanh nghiệp Dẫn đầu (BSA/LBC) trước tiên ghi nhận đóng góp trách nhiệm xã hội của nhóm doanh nghiệp sớm nhận thức giá trị của ĐMST toàn diện trong sản xuất và kinh doanh. Đây là những tổ chức kinh doanh không ngừng cải thiện chất lượng phục vụ nhu cầu tiêu dùng xã hội từ các nỗ lực ĐMST và hơn thế, còn sẵn sàng chia sẻ hiểu biết và câu chuyện thực tiễn trong quá trình lao động sáng tạo. Kết quả i2Metrix 2014 - doanh nghiệp Việt Nam sử dụng lý thuyết và công cụ quản trị ĐMST của Việt Nam - còn là hành động minh chứng cho tinh thần "người Việt dùng hàng Việt" rõ ràng và cụ thể.

\section{Phương pháp luận khảo sát Đánh giá Năng lực Sáng tạo}

19 doanh nghiệp đầu tiên tham gia khảo sát i2Metrix hoạt động trong 8 nhóm ngành sản xuất. Nhóm doanh nghiệp này có quy mô tổng tài sản ước trên 24.000 tỷ đồng, sử dụng trên 28.000 lao động và ước đạt doanh thu 35.000 tỷ đồng trong năm 2013.

Ba nhóm ngành có số doanh nghiệp tham gia nhiều nhất là Gia dụng, Dược phẩm và Thực phẩm. Dựa theo hình biểu diễn 10 kích thước ĐMST của từng ngành thì có thể thấy Dược phẩm và Thực phẩm bao ra ngoài Gia dụng. Kết quả này này hợp lý với yêu cầu thực tiễn bởi dược và thực phẩm là hai ngành có ảnh hưởng trực tiếp tới sức khỏe cộng đồng. 


\title{
i2-Metrix Đánh giá Năng lực Sáng tạo Doanh nghiệp
}

\author{
1- Output: Thành tụu/Lợi ích sinh ra từ đỗi mới-sáng tạo \\ 2- Innovator: Nguồn nhân lụcc sáng tạo \\ 3- F-Resources: Nguồn lực tài chính/đâu tư cho hoạt động đồi mới-sáng tạo và quá trình "khởi nghiệp định hướng \\ đồi mới" nội bộ.
}

\begin{abstract}
4- Supports: Mức độ hỗ trợ mang tính chất tổ chức với đối với định hướng đỗ mới-sáng tạo
5- Differentiation: Mức độ tạo ra sự chuyên biệt hóa và khác biệt trong cạnh tranh thị trường

6- Trend-setting: Tính thích ứng với xu hướng nhu câu, tâm nhìn vê chu kỳ sống của sản phẩm, sức ảnh hưởng xu hướng (khả năng tạo xu hướng mới cho thị trường)
\end{abstract}

7- Multi-filtering: Năng lực xử lý thông tin đa tâng tạo hiểu biết thấu đáo/sâu sắc để chuẩn bị cho quá trình đồi mớisáng tạo

8- Mindsponge: Năng lụ̣c xây dụnng lơi giá trị văn hóa thích ứng với thay đồi và định hướng đỗi mới-sáng tạo

9- Implementation: Khả năng điểu phới nhịp nhàng để một ỵ tưởng được quyết tâm đâu tư đến đích sản phẩm, đưa ra thị trường và cải tiến cho tới bán hàng (từ ý tưởng đến phân phới)

10- C-readiness: Năng lực quan sát, dự báo nguy cơ và đánh giá khả năng đáp ứng nguy cơ từ bên trong doanh nghiệp/tổ chức (như cắt lỗ, chuyển hướng, tái định dạng hoạt động)

Courtesy: Author Prof. Nancy K. Napier; DHVP Research \& Consultancy,

Cùng đánh giá năng lực ĐMST của doanh nghiệp có nhóm triển khai i2Metrix BSA-DHVP, đại diện các doanh nghiệp và các nhà báo thành viên CLB Phóng viên Kinh tế.

Đại diện doanh nghiệp tham gia khảo sát i2Metrix 2014: ông Nguyễn Thể Hà (Cty TNHH Cơ Khí Công Nông Nghiệp Büi Văn Ngọ), ông Phạm Hồng Phú (CTCP Công Nghiệp Cao Su Miền Nam CSM:HOSE), ông Kao Siêu Lực (Doanh Nghiệp Tư Nhân Bánh Kẹo Á Châu), bà Đặng Thị Kiều Nguyệt (CTCP Giấy Sài Gòn), ông Nguyễn Mạnh Dũng (CTCP Thiết Bị Nhà Bếp Vina), ông Trần Quốc Toản (CTCP Bóng Đèn Điện Quang - DQC:HOSE), ông Nguyễn Bá Lâm (CTCP Sản Xuất Nhựa Duy Tân), ông Lý Ngọc Minh (Cty TNHH Minh Long I), bà Cao Thị Ngọc Dung và ông Nguyễn Vũ Phan (CTCP Vàng Bac Đá Quý Phú Nhuận - PNJ:HOSE), bà Nguyễn Thị Hồng Trang (CTCP Thời Trang Sơn Kim), ông Nguyễn Đình Tâm (CTCP Tập Đoàn Thiên Long- TLG:HOSE), các bà Vũ Thị Thuận và Đỗ Thị Hạnh Lê (CTCP Traphaco - TRA:HOSE), ông Lê Chánh Đạo (CTCP Dược Hậu Giang - DHG:HOSE), ông Lê Nhã Phương (CTCP Xuất Nhập Khẩu Y Tế Domesco - DMC: HOSE), ông Nguyễn Lâm Viên (CTCP Vinamit), ông Lê Nguyên Hòa (CTCP Thực Phẩm Dinh Dướng Nutifood), bà Ngô Thị Hoàng Mai (CTCP Chế Biến Thủy Hải Sản Liên Thành), bà Nguyễn Thị Phương Ninh và ông Nguyễn Ngọc Đăng Khoa (Cty TNHH MTV Việt Nam Kỹ Nghệ Súc Sản - Vissan), các bà Lê Thị Thanh Lâm và Nguyễn Thị Phương Thủy (CTCP Sài Gòn Food).

Các nhà báo tham gia khảo sát i2Metrix 2014: Quang Trường (HTV), Phương Nhi (VITV), Phương Hiền $(F B N C)$, Xuân Đào $(V O H)$, Thế Phong (VOH -FM99.9), Minh Hạnh (VOV), Mỹ Phương (TTXVN, Phân xã Tp. Hồ Chí Minh), Nguyễn Hải (Người Lao động), Các Ngọc (Sài Gòn Tiếp Thị), Thanh Hương (Nhịp Cầu Đầu Tư), Hồng Nga (Doanh nhân Sài Gòn), Lâm Hiểu Đông (Sài Gòn Giải Phóng Hoa Văn), Nguyễn Thanh Tân (Đầu Tư), Xuân Hương (VietNamNews), Nguyễn Tấn Hùng (Lao động Xã hội), và Thanh Giang (Đại Đoàn Kết).

\section{Bí quyết ĐMST từ nhóm doanh nghiệp dẫn đầu}

Khi xem xét ĐMST như một quá trình, 10 kích thước của i2Metrix phân thành ba nhóm:

Nhóm "Đầu vào" gồm 02 kích thước: Innovator và F-Resources

Nhóm "Đầu ra" gồm 03 kích thước: Output, Differentiation và Trend-Setting

Nhóm "Hỗ trợ" gồm 05 kích thước: C-Readiness, Multi-Filtering, Implementation, Support và 


\section{Mindsponge}

Độ đo bình quân của các kích thước tập trung trong khoảng từ 7.5 đến 8.5 của nhóm doanh nghiệp khảo sát là tín hiệu đáng phấn khởi và cần phải có. Bởi lẽ, đây là nhóm những doanh nghiệp có thương hiệu mạnh, năng lực cạnh tranh dẫn đầu trong từng ngành.

\section{Xét riêng nhóm "Đầu ra":}

Đóng góp trực tiếp - thể hiện qua đóng góp ĐMST vào doanh số/lợi nhuận/chi phí tiết kiệm được - vào kết quả kinh doanh của doanh nghiệp còn ở mức khiêm tốn. Tuy nhiên, ĐMST góp phần rất đáng kể tạo ra sự khác biệt của doanh nghiệp, sản phẩm của doanh nghiệp trong cạnh tranh thương trường cũng như tính thích ứng với xu hướng nhu cầu, tầm nhìn về chu kỳ sống của sản phẩm và khả năng tạo nhu cầu/sở thích tiêu dùng mới của doanh nghiệp. Thực tế này hợp lý.

Dòng doanh thu lớn nhất của doanh nghiệp, đặc biệt là các doanh nghiệp đã "thành danh" trên thị trường, lẽ thường, đến từ những sản phẩm đã đạt tới mức độ chín muồi chứ không phải những sản phẩm mới lần đầu xuất hiện. Sản phẩm mới chào bán ra công chúng dù thu hút sự quan tâm nhưng sẽ phải đợi tới những chu kỳ kinh doanh tiếp theo mới trở thành mặt hàng tạo doanh số chủ lực.

Ý nghĩa "sống còn" của ĐMST thể hiện không chỉ ở doanh số mà còn cả sự khác biệt và khả năng đi đúng hướng của thị trường. Doanh số cao trong một kỳ kinh doanh, có nhiều lúc, không quan trọng bằng kịp nhận diện và chuẩn bị đáp ứng nhu cầu tiêu dùng mới sẽ xuất hiện ở chu kỳ tiếp sau. Bài học về cú suýt ngã quỵ của Microsoft nếu bỏ qua làn sóng Internet là một minh họa điển hình.

\section{Xét riêng nhóm "Đầu vào":}

Các doanh nghiệp tham gia khảo sát dồi dào nguồn lực (cả con người và tài chính) cho ĐMST. Độ đo chung cho mẫu khảo sát là 8,1 và 8,6 tương ứng với Innovator và F-Resources.

Về nguồn lực con người, vai trò của người lãnh đạo doanh nghiệp có ý nghĩa quyết định tới toàn bộ hoạt động ĐMST trong doanh nghiệp. Ngay từ những ngày kinh doanh đầu tiên, dù trong hoàn cảnh nào, những người đứng đầu doanh nghiệp cũng luôn xác định ĐMST là yếu tố mang tính sống còn.

Khá nhiều doanh nghiệp trong mẫu khảo sát đang hoạt động theo kiểu doanh nghiệp gia đình và trong giai đoạn chuyển giao thế hệ (có doanh nghiệp đang chuẩn bị năng lực cho thế hệ sau; có doanh nghiệp đã bắt đầu chuyển giao từng phần; có doanh nghiệp đã hoàn tất chuyển giao). Đặc trưng nổi bật này của mẫu khảo sát đặt câu hỏi nghiên cứu ứng dụng lý thuyết quản trị về mô hình "tổ chim-cái trứng".

Cách thức lặp lại là: Cha, mẹ gây dựng doanh nghiệp. Khi các con trưởng thành thì sẽ được định hướng và phân bổ đi học các ngành khác nhau để tớl lúc học xong sẽ quay về quản lý các bộ phận căn bản nhất của doanh nghiệp. Thường thì đó là các ngành: quản trị kinh doanh và tài chính (để quản lý và điều hành chung), một ngành kỹ thuật xương sống của doanh nghiệp (công ty cơ khí thì học chế tạo máy, công ty thực phẩm thì là hóa thực phẩm), một ngành về thị trường (như marketing, thiết kế mẫu).

"Chiến lược gia đình" kiểu này đưa ra vài gợi ý:

Vấn đề "niềm tin chiến lược" rất được coi trọng trong các doanh nghiệp gia đình. Niềm tin này chỉ trao cho thành viên của gia đình.

Lãnh đạo các công ty gia đình nhận thức đầy đủ về vai trò quan trọng của kỹ nghệ quản trị. Quản lý tốt cần thiết không kém gì có năng lực sản xuất tốt. Vì thế, dù thường khởi đầu bằng thế mạnh sản xuất nhưng các bậc cha, chú khi chuyển giao thế hệ đều rất quan tâm tới năng lực điều hành và quản trị bao quát.

Tuy vẫn giữ truyền thống gia đình nhưng phương thức quản trị hiện đại đang dần định hình trong các doanh nghiệp này.

Các doanh nghiệp gia đình có năng lực nạp-xả giá trị văn hóa và tính thích ứng với biến động môi trường kinh doanh (mindsponge) được tôi luyện qua nhiều lần dịch chuyển của môi trường kinh doanh, như trưởng thành từ doanh nghiệp tư nhân (thời kỳ kinh tế thị trường kiểu Mỹ), sang hộ cá thể (thời kỳ kinh tế kế hoạch), rồi trở lại doanh nghiệp tư nhân (thời kỳ Đổi Mới), hướng tới mô hình công ty đại chúng (cổ phần hóa, niêm yết trên TTCK), và chuẩn bị nền tảng cho mô hình kinh doanh toàn cầu.

Về tài chính, các doanh nghiệp đều dành ưu tiên cao cho các nỗ lực ĐMST. Ngoài thực tế có chỉ số 
Nợ/(Tổng Nợ và Tài sản) ở mức dưới $5 \%$, gần như tất cả doanh nghiệp tham gia khảo sát sử dụng nguồn vốn tự có hoặc tích lũy từ lợi nhuận qua các năm để tài trợ cho ĐMST.

ĐMST được xem công việc khó, đòi hỏi nỗ lực đầu tư lâu dài, song có ý nghĩa sống còn với doanh nghiệp trong duy trì ưu thế hiện tại trên thương trường vừa kiến tạo tương lai doanh nghiệp.

Ông Cổ Gia Thọ (CTCP Tập Đoàn Thiên Long- TLG:HOSE): "Không thể nói vì doanh nghiệp còn nghèo mà không đầu tư cho R\&D nếu muốn công ty còn tiếp tục sống và phát triển".

\section{Xét riêng nhóm "Hỗ trọ":}

05 kích thước thuộc nhóm "Hỗ trợ" còn có thể xem như những đầu vào gián tiếp của quá trình ĐMST. Nếu hai kích thước "Đầu vào" (nhân lực và tài lực) có thể kiểm điểm tương đối dễ dàng qua số lượng và quy mô thì nhóm hỗ trợ cung cấp các công cự/phương tiện để hai đầu vào kể trên được khai thác với hiệu suất tốt nhất. Hơn thế, nhóm kích thước này kiến thiết nên hệ sinh thái ĐMST từ bên trong doanh nghiệp, tích lũy năng lượng ĐMST sinh ra trong quá trình vận hành sản xuất-kinh doanh của doanh nghiệp trong ràng buộc hữu hạn của nguồn lực đầu vào.

Lãnh đạo PNJ và SG Food đã có thêm nhiều thông tin gợi ý giải pháp và sản phẩm sáng tạo mới mà không cần bổ sung nhân lực cho R\&D hay tăng ngân sách để tìm hiểu công nghệ hoặc nhu cầu thị trường. Thay vì huy động nhiều hơn đầu vào "vật chất", lãnh đạo hai doanh nghiệp này gia tăng lượng thông tin đầu vào cho quá trình lọc thông tin đa tầng[1] bằng việc tăng cường tiếp xúc, trao đổi với đội ngũ (kể từ người lao động có vị trí thấp nhất trong chuỗi sản xuất) hoặc tổ chức các cuộc thi trình bày ý tưởng thành các sản phẩm mẫu.

\section{Bài học thành công từ 19 doanh nghiệp khảo sát:}

\section{Ra đời từ ĐMST}

\section{Tồn tại nhờ vận dụng ĐMST}

\section{Phát triển bền vững bằng động cơ kép sáng tạo-khởi nghiệp}

Ý nghĩa ứng dụng của i2Metrix: công cụ và phương tiện để ĐMST không còn là khối trừu tượng mà trở thành quá trình lao động có thể học tập được, rèn luyện được và quản trị được.

\section{Doanh nghiệp chống "ngộ độc" ĐMST}

Như đã phân tích với Nhóm "Đầu ra", những thành quả hữu hình của ĐMST (sản phẩm mới, bằng phát minh-sáng chế, giải pháp kinh doanh) không phải mục tiêu duy nhất, lại càng không phải ưu tiên cao nhất, của quá trình lao động sáng tạo. ĐMST, cần được hiểu đúng, là cấu phần quan trọng của quản trị chiến lược.

Cái gì quá cũng đều không tốt. Học quá nhiều dễ thành "ngộ chữ". Ăn quá nhiều thịt dễ mắc bệnh gút. Với doanh nghiệp cũng vậy, quá tập trung vào những phát kiến mới, liên tiếp đưa sản phẩm mới ra thị trường sẽ dẫn tới "ngộ độc ĐMST". Một giải pháp để doanh nghiệp không cần ngần ngại với các phát kiến đó là tuân thủ một kỷ luật sáng tạo liên ngành-liên lĩnh vực, theo đó hoạt động sáng tạo/phát kiến phải gắn chặt với quá trình hoạch định và triển khai chiến lược.

Như người ta thường nói, quản trị là một khoa học và cũng là nghệ thuật. Ở đây, là nghệ thuật giữ cân bằng (art of balancing). Cân bằng để biết "không bỏ tất cả trứng vào một giỏ" cũng như biết tuân thủ kỷ luật cân nhắc chi phí-lợi ích để ra loại bỏ những yếu tố cảm xúc mà ra quyết định đúng đắn. Cân bằng khác xa với lưỡng lự, không quyết đoán như chú lừa của Buridan.

M. Jackson (1958-2009) trở thành ông vua nhạc Pop nhờ những bước nhảy điêu luyện và khả năng giữ thăng bằng tuyệt vời. Điều thú vị: M.J. cũng là một nhà phát minh với điệu nhảy nghiêng ở góc 45 độ.

Kết quả i2Metrix2014 cho thấy không xuất hiện nguy cơ ngộ độc ĐMST trong mẫu doanh nghiệp khảo sát. Khó mà nói rằng thành tựu ĐMST của nhóm doanh nghiệp này chưa đủ nhiều bởi đây đều là các thương hiệu đã thành công trên thị trường. Quan điểm và thái độ chủ động của doanh nghiệp - trực 
tiếp là của người lãnh đạo doanh nghiệp - mới là nguyên nhân trọng yếu.

Trước tiên, tinh thần khởi nghiệp mạnh mẽ của người đứng đầu doanh nghiệp không chỉ tạo lực kéo cho con tầu kinh doanh mà còn triệt tiêu sự thỏa mãn và tự bằng lòng. Bà $\mathrm{CaO}$ Thị Ngọc Dung (PNJ:HOSE) trong lúc trao đổi nhiều lần nhắc tới câu danh ngôn của Voltaire (1694-1778) "Tốt nhất là kẻ thù của tốt (The best is the enemy of the good)".

Cùng chia sẻ quan điểm phải biết tiết chế và sử dụng kết quả ĐMST đúng thời điểm, ông Nguyễn Lâm Viên (Vinamit) cho biết: tại Vinamit, ĐMST phải làm liên tục, còn đem xài lúc nào thì phải tính kỹ. Khi doanh số sản phẩm truyền thống chững lại là lúc tung sản phẩm cải tiến (bổ sung tính năng, điều chỉnh khẩu vị cho sản phẩm truyền thống). Lúc nhu cầu khám phá mới lạ của người tiêu dùng lộ ra là khi cần mau chóng giới thiệu sản phẩm mới. Phải chờ đội ngũ tích lũy đủ năng lực thì mới đưa giải pháp công nghệ tiên tiến vào sản xuất.

Còn với NaMiLux và Traphaco thì ĐMST phải đi liền với tinh thần trách nhiệm. Đó là trách nhiệm duy trì một nguồn cung ổn định cho các đối tác và người tiêu dùng của ông Nguyễn Mạnh Dũng (NaMiLux). Đội ngũ NaMiLux luôn phải tìm tòi các giải pháp cải tiến và đổi mới nhưng để ứng dụng phải trải qua một quá trình thử nghiệm và kiểm tra ngặt nghèo, kết hợp với tham vấn ý kiến chuyên môn của đối tác quốc tế. Hay với Traphaco, ĐMST không thể tiến hành bằng việc thay thế hàng chục, thậm chí hàng trăm, công nhân bằng dây chuyền tự động hóa. Thay vào đó, ĐMST phải là những cách bán hàng thông minh hơn, gần gũi hơn với người tiêu dùng đặc biệt (những người đang đau ốm).

Mike Maddock[2] cho rằng, thật không may, nguyên nhân chính khiến cho hàng loạt doanh nhân gặp thất bại trên thương trường là do không phân biệt được sự khác nhau của hai khái niệm "sáng chế" và "đổi mới." Nhà sáng chế (inventor) tạo khởi đầu với ý tưởng và nỗ lực tìm kiếm những người có nhu cầu với ý tưởng đó. Người cải tiến (innovator) tài giỏi trước tiên tìm ra nhu cầu LớN NHÂT, rồi sau đó tạo giải pháp để đáp ứng nhu cầu đó.

Thách thức khởi đầu của một sáng chế là phải tìm ra ý tưởng mới, nhưng không cần thiết số đông phải sẵn sàng chi trả cho sáng chế đó.

Nghĩ ra những ý tưởng mới tương đối dễ dàng, thậm chí có thể nảy ra 10 ý tưởng mới chỉ trong vòng 5 phút. Đáp ứng nhu cầu thị trường luôn khó khăn nhưng đem lại lợi nhuận rất lớn, nên các doanh nhân có xu hướng chọn "sáng chế" thay vì "đổi mới." Đây là điều Mike gọi là "bẫy sáng chế" - một thất bại tiềm ẩn.

ĐMST là một phần quan trọng trong kinh doanh. Dù là ở ngành công nghiệp nào, ĐMST cũng tạo nên sự khác biệt cho một công ty. Khả năng tạo ra sản phẩm và dịch vụ mới là một trong những tài sản đáng giá nhất của doanh nghiệp. Tuy nhiên, ĐMST không phải lúc nào cũng cần thiết. Có rất nhiều câu chuyện về sự đổi mới đem lại thành công cho công ty nhưng cũng có những trường hợp đổi mới quá đà lại gây ra tổn thất. Hai trường hợp nổi bật hơn cả là sản phẩm Big Mac của Mc Donald's và sản phẩm mới của Coke.[2]

Mc Donald's là một trong những công ty lớn, nổi tiếng và có lợi nhuận lớn nhất trên thế giới. Big Mac một loại bánh kẹp nhiều tầng có nước xốt đặc biệt là mặt hàng chủ lực của Mc Donald's trong suốt nhiều năm qua. Dù thực đơn của Mc Donald's mỗi năm đều có sự thay đổi nhưng không thể thiếu được loại bánh Big Mac mà khách hàng rất yêu thích. Đây là một ví dụ hoàn hảo cho việc không cần quá nhiều đổi mới mà vẫn mang đến thành công. Đã qua 45 năm, bao bì có thay đổi nhưng chiếc bánh Big Mac thì vẫn giống như ngày nào.

$A B C$ Bakery là nhà cung cấp độc quyền bánh burger cho nhiều thương hiệu thức ăn nhanh tại Việt Nam như KFC, Lotteria, Burger King.. và cả Mc Donald's.

Coca-Cola cũng là một sản phẩm rất nổi tiếng trên thế giới của Coke. Tuy nhiên, trong những năm 1980, Coke đã gặp khó khăn khi cạnh tranh với đối thủ chính - Pepsi. Doanh số và thị phần giảm dần khiến Coke phải nghĩ đến việc đổi mới. Công ty này đã chi hàng triệu đôla để tạo ra một công thức hoàn toàn mới để thay đổi hương vị của sản phẩm chính với hi vọng thu hút được khách hàng trẻ tuổi ưa thích đồ ngọt. Thế nhưng khách hàng đã có phản ứng tiêu cực với sản phẩm này. Vấn đề ở đây là khách hàng đã quá quen thuộc với hương vị của sản phẩm cũ; họ mua sản phẩm bởi công thức chế biến riêng đã được lưu giữ cả một thế kỷ. Cuối cùng công thức nguyên bản lại được áp dụng và doanh số của sản phẩm cũ tăng cao, thậm chí còn hơn kỳ vọng. Phản ứng với sản phẩm mới quá tệ đến mức nó làm tăng cả doanh số của sản phẩm cũ.

Hai câu chuyện của McDonald và CocaCola vẫn thường được nhắc tới như phản ví dụ về hiệu quả của ĐMST. Nhưng cần thiết phải đặt câu hỏi: Làm sao có thể bán một sản phẩm không có gì đổi khác sau hàng chục, thậm chí là hàng trăm năm mà vẫn giữ được vị thế thương hiệu hàng đầu thể giới? Đổi mới 
và Sáng tạo nhất định nằm ở đâu đó trong kỹ nghệ quản trị, cách thức tổ chức sản xuất và phân phối.

Cocacola còn nổi tiếng trong lý thuyết quản trị khi hãng mạnh dạn thay đổi người lãnh đạo - cũng là thay đổi tư duy lãnh đạo (mindset) - của mình. Thay vì sử dụng Tổng Giám đốc là người Mỹ, để duy trì phong cách Mỹ trong hệ thống Cocacola toàn cầu, hãng đã bổ nhiệm Tổng Giám đốc là người Úc, từng phụ trách Cocacola Úc, để thích ứng với hoạt động trên quy mô toàn cầu của chính Cocacola. Ở đây, CocaCola đã kích hoạt cơ chế nạp-xả giá trị văn hóa (mindsponge) để tìm ra giải pháp hiệu quả trong tiếp biến văn hóa (acculturation).[4] Douglas $\mathrm{N}$. Daft được bầu làm Chủ tịch kiêm CEO Coca-Cola vào tháng 2-2000. Sinh tại Australia, Daft làm việc tại các bộ phận bên ngoài nước Mỹ của tập đoàn trong phần lớn sự nghiệp cho tới khi nhận chức CEO. CEO tiền nhiệm - Douglas Ivester - đã buộc phải rời vị trị một phần bởi sự thiếu nhạy bén với những vấn đề về sự đa dạng trên các thị trường bên trong và bên ngoài nước Mỹ.[11]

Với kinh nghiệm và hiểu biết của mình, Daft bắt đầu định hướng Coca-Cola tập trung vào từng vùng và khu vực. Coca-cola chuyển trọng tâm sang "tư duy địa phương, hành động địa phương" với nhằm khai thác tốt nhất sự khác biệt trong thị hiếu tiêu dùng tại mỗi quốc gia.

Tiếp biến văn hóa thể hiện rất rõ trong ghi chép của Nguyễn Thị Ngọc Hải về thành công của ông Lý Ngọc Minh:

.. Ông vẫn "rong chơi" theo kiểu của mình: trước hết phải làm. Sáng dậy làm việc riết tới chiều, phải đương đầu với lạm phát. "Lúc khó khăn bão tố không ai căng buồm ra khơi. Tôi cũng vậy, dù do xuất khẩu là chính nền không bị ảnh hưởng nhiều. Hàng vẫn ổn, tăng doanh số nhưng trong cảnh khổ chung: giá nhiên liệu tăng, lương công nhân tăng. Nhưng mình có tăng giá sản phẩm không?". Bài toàn tăng giá ai cũng biết làm nhưng Minh Long chấp nhận không tăng, chỉ điều chỉnh sản phẩm, từ lúc ra đời đến nay vẫn giá cũ như bộ đồ trà. Chữ Tín của người Hoa, theo ông, là "do hoàn cảnh thôi, ra xứ người sống, đặc thù hơn người mới tồn tại được. Hồi nhỏ tôi cần khuôn thạch cao, tới hãng Đức Phát xin mua thiếu, ông chủ hỏi: Ba mày là ai? Khi nghe đáp, ông bảo: Con ông Lý Kim hả? Ba mày đàng hoàng, cứ lấy bao nhiêu cũng được". Người bây giờ thì bảo: "Minh Long nói, không cần giấy, hứa nói miệng cũng giữ".

\section{Sáng tạo trong môi trường kỷ luật}

Doanh nghiệp - cũng như mọi tổ chức bất kỳ - luôn đề cao tính kỷ luật. Các doanh nghiệp Việt Nam lại càng đề cao sự tôn trọng thứ bậc trong tổ chức. Đặc trưng văn hóa này có cản trở sáng tạo? Theo Napier và Nilsson (2008) thì "Khồng", bởi quan sát các tổ chức giàu tính sáng tạo cũng như năng suất kinh tế cao ghi nhận một điểm chung: Kỷ luật.[5]

Để đạt tới sự sáng tạo có ba kỷ luật cần tuân thủ: (i) suy nghĩ vượt ra ngoài khuôn khổ kỷ luật nghề nghiệp quen thuộc (out of discipline thinking), (ii) thực hành với năng lực chuyên môn tốt nhất trong kỷ luật nghề nghiệp (within discipline expertise) và (iii) thực thi quá trình lao động sáng tạo theo một quy trình đầy tính kỷ luật (a disciplined process).

Suy nghĩ vượt ra ngoài kỷ luật quan tâm tới năng lực xem xét và tìm kiếm ý tưởng mới ở phạm vi bên ngoài tổ chức, lĩnh vực hoạt động, ngành, hay bất kỳ giới hạn nào mà tổ chức/cá nhân tự đặt ra cho mình trước đó. Người có năng lực suy nghĩ vượt ra ngoài kỷ luật tiếp nhận thông tin từ những nguồn nằm bên ngoài phạm vi và lĩnh vực quen thuộc, rồi sau đó tìm cách hiểu rõ làm sao có thể áp dụng những ý tưởng/thông tin đó trong tình huống cụ thể của mình.

Thực hành với năng lực chuyên môn tốt nhất đề cập tới cách thức mà cá nhân trở thành người giỏi nhất trong lĩnh vực của mình và sau đó, với nền tảng năng lực chuyên môn cao, tiếp tục suy nghĩ ngày càng sáng tạo hơn. Điểm mấu chốt ở đây là, khi những người giỏi nhất trong các lînh vực chuyên môn (có thể giống hoặc khác nhau) cạnh tranh và/hoặc hợp tác cùng nhau, họ có thể học và nhanh chóng cải thiện khả năng của mình từ chính những người khác. Kết quả quá trình học và tự hoàn thiện từ quan sát năng lực chuyên môn tốt nhất ở người các (đối thủ cạnh tranh hay đồng nghiệp hợp tác) là những ý tưởng mới.

Thực thi quá trình lao động sáng tạo có kỷ luật nghĩa là tổ chức sử dụng các quy tắc, cấu trúc, vận hành quy củ, tuần tự để tạo điều kiện thuận lợi cho sáng tạo nảy nở. Khi mọi việc đều được cắt đặt ngăn nắp, cá nhân được hoàn toàn tập trung năng lượng vào việc tư duy và tìm kiếm các ý tưởng mới. 
tính chuyên sâu trong một số lĩnh vực. Nhưng nhiều người cảm thấy kỷ luật thứ ba rất khó ứng dụng. Thay vì cho phép dành thời gian và tạo ra hệ thống để phát triển các ý tưởng mới, có vẻ như dễ dàng hơn nếu nhảy cóc tới các ý tưởng chứ không nghiền ngẫm, nung nấu, hay kiểm định nữa. Thực tiễn cho thấy, phần đông lo đánh mất cơ hội, nhưng lại không mảy may lo việc thất bại với ý tưởng ngay khi đã có cơ hội. Xét kỹ ra, bằng việc dành đủ thời gian cho sáng tạo theo một phương pháp có tổ chức, doanh nghiệp có thể tiết kiệm thời gian về sau và thu nhận được nhiều ý tưởng có thể hữu ích hơn nữa.

Christensen và Overdoft (2000) cũng nhất trí rằng, sáng tạo trong các doanh nghiệp đã phát triển hoàn chỉnh là rất khó khăn.[6] Nghịch lý là đội ngũ nhân sự chất lượng cao khi được đặt trong môi trường làm việc đầy đủ tiện nghi lại không thể đưa ra các giải pháp cải tiến và đổi mới trước áp lực không được phép thất bại. Việc doanh nghiệp có thể hay không thể làm gì phụ thuộc ba yếu tố: (i) nguồn lực doanh nghiệp có gì để thực hiện, (ii) quy trình - doanh nghiệp tổ chức thực hiện như thế nào, và (iii) giá trị - yếu tố văn hóa này thể hiện qua quyết định sẽ ưu tiên làm gì của mỗi thành viên doanh nghiệp. Doanh nghiệp có quy mô càng lớn thì việc giáo dục và huấn luyện nhân sự để đội ngũ đạt tới đồng nhất về giá trị càng quan trọng, thậm chí còn hơn cả hai yếu tố trước. Khi chinh phục thành tựu mới trở thành giá trị chung của doanh nghiệp, cơ hội giải quyết nghịch lý xuất hiện.

Nhà khoa học chính trị và kinh tế lỗi lạc Joseph A. Schumpeter (1883-1950) đặc biệt nhấn mạnh vai trò của khởi nghiệp - gắn liền với sáng tạo - trong nền kinh tế. Nền kinh tế trải qua chu kỳ tăng trưởng-suy thoái dài hạn bởi nó hoàn toàn dựa trên các phát minh và sáng tạo khoa học. Giai đoạn mở rộng kinh tế được tạo ra nhờ các sáng chế làm tăng năng suất lao động và khuyến khích đầu tư. Tuy nhiên, khi các nhà đầu tư không còn nhiều cơ hội để bỏ vốn, nền kinh tế sẽ đi vào giai đoạn suy giảm, một số doanh nghiệp đóng cửa hoặc phá sản. Tình trạng này sẽ kéo dài cho tới khi có những phát minh và cải tiến mới xuất hiện trong quá trình phá hủy kiến tạo: sản phẩm và phương pháp sản xuất cũ bị phá bỏ, số lượng việc làm cần thiết để tạo ra một sản phẩm từng được sản xuất giảm đi nhưng đồng thời nền kinh tế bắt đầu một chu kỳ mới dựa trên các sản phẩm mới và đầu vào sản xuất mới. Một nền kinh tế muốn khỏe mạnh phải tạo môi trường để quá trình này sản sinh và tiếp nối liên tục.

MacDonald (2008)[7] tin tưởng việc gây dựng văn hóa khuyến khích và thúc đẩy sáng tạo ngay trong những hệ thống chặt chẽ và quan liêu nhất là hoàn toàn khả thi. Đồng ý với nhận định rằng các ý tưởng đổi mới chỉ có thể phát triển khi người đứng đầu doanh nghiệp có quan điểm cởi mở và chủ trương khuyến khích nỗ lực sáng tạo của đội ngũ, nhưng MacDonald cũng nhấn mạnh rằng, điều kiện tiên quyết phải là mong muốn sáng tạo từ chính mỗi thành viên của doanh nghiệp. Với số đông thành viên chia sẻ giá trị vươn tới những thành tựu mới, văn hóa sáng tạo sẽ hình thành trong doanh nghiệp mà người chủ hay người quản lý cấp cao cũng chỉ là một thành viên của cộng đồng.

Biến giấc mơ khởi nghiệp thành hiện thực không chỉ có một cách duy nhất là lập doanh nghiệp hay tự triển khai một hoạt động kinh doanh. Có những người làm chủ doanh nghiệp mà không hề có tố chất khởi nghiệp. Đồng thời, cũng có rất nhiều người khởi nghiệp đang làm việc trong những đơn vị kinh doanh, hay kể cả các tô̂ chức hành chính. Trong cuốn sách hơn 250 trang của mình, Mac Donald trình bày chi tiết 11 quy tắc để định hình và phát triển tố chất khởi nghiệp ở mỗi cá nhân với chỉ một thông điệp bao trùm: vững tin rằng lựa chọn khởi nghiệp là suy nghĩ đúng đắn, và với niềm tin này hãy hành động quyết liệt, không ngừng cải thiện nhận thức về các cơ hội, và sẵn sàng chấp nhận bất trắc. Phần thưởng dành cho người người khởi nghiệp là sự độc lập về kinh tế và quyền tự định đoạt sự nghiệp của chính mình.

Trong mẫu khảo sát 19 doanh nghiệp dẫn đầu, người lãnh đạo doanh nghiệp có vai trò nổi bật trong thành công ĐMST. Thực tế này gợi lên băn khoăn về tính bền vững của năng lực ĐMST trong các doanh nghiệp và khả năng tiếp nối thành công của thế hệ kế cận. Phương pháp tổ chức quá trình lao động sáng tạo và tính kỷ luật trong thực thi phương pháp mà doanh nghiệp đang theo đuổi là dấu hiệu đáng tin cậy phản chiếu sức mạnh cạnh tranh ĐMST của doanh nghiệp trong tương lai.

Câu chuyện thành công của Sứ Minh Long I tiêu biểu cho kỷ luật lao động sáng tạo. Bắt đầu trao đổi với i2Metrix, ông Lý Ngọc Minh khẳng định ngay: Không nỗ lực ĐMST nào tại Minh Long I không thành công. Lý do của ông giản dị: Minh Long I đã làm thì tới cùng.

Ví dụ có rất nhiều. Từ hơn 10 năm trước sự kiện kỷ niệm 1000 năm Thăng Long - Hà Nội, Minh Long đã phôi thai ý tưởng về một sản phẩm gốm đỉnh cao để đời. Sau đó là 5-6 năm tìm tòi ý tưởng. Tiếp theo là 3-4 làm thử, hỏng, và làm lại. Tận tới sáng ngày ban giao, khi chiếc xe chuyên chở lùi vào trong xưởng thì chiếc chén ngọc - chỉ nung một lần mà rất hoàn chỉnh - mới được ra đời. Hoặc với sản phẩm ngựa cho năm Giáp Ngọ, Minh Long I đã bắt đầu 20 năm trước nhưng tới giờ mới hoàn thiện quy trình nặn tượng tới mức thợ lành nghề đều làm được ngay. Hay như, sau 15 năm tham dự hội chợ gốm sứ quốc tế tại Frankfurt - vất vả và phí tổn rất nhiều - nhưng phải tới "Abeiente The Snow 2014" (từ ngày 7 đến 11-2-2014) Minh Long I mới co được kết quả như mong muốn. 
Nỗ lực bền bì trên những hành trình nhiều thập kỷ không chỉ là ý chí chủ quan của người đứng đầu doanh nghiệp. Ba kỷ luật lao động sáng tạo đã được Napier \& Nilsson (2008) đúc kết lần lượt hiện ra.

Minh Long I chỉ tới quyết định tham dự hội chợ Frankfurt sau khi đã tìm hiểu kỹ và khẳng định: đây là hội chợ nổi tiếng nhất, lâu đời nhất, có sự tham gia của những thương hiệu lớn nhất thế giới và có người mua danh giá nhất thế giới. [Kỷ luật về tụ hội những điểm tốt nhất.]

Tâm đắc với kỷ luật này, ông Lý Ngọc Minh chia sẻ: Minh Long I luôn là sân chơi của những con người giỏi nhất. Điều Minh Long I đem lại chưa phải lợi ích vật chất lớn nhất nhưng là cơ hội để thỏa chí, để thực hiện ước mơ. Minh Long I là sân chơi mà không tay chơi giỏi giang nào muốn vắng mặt. Nguồn nhân lực cho ĐMST của Minh Long I, theo đó, phân tán ở mọi cấp độ, tại mỗi bộ phận.

Trong nhiều năm đầu, Minh Long I không bán được sản phẩm nào trong những lần tới Hội chợ Frankfurt. Điều này không nằm ngoài dự tính của ông Lý Ngọc Minh. Lẽ thường tình, tới hội chợ thì giới thiệu và ráng mà bán sản phẩm, nhưng với Minh Long I, dự hội chợ còn là dịp quan sát cách làm của những đối thủ hàng đầu thế giới: họ có sản phẩm thế nào? bày bán ra sao? trình bày thuyết phục người mua như nào? ai mua hàng của họ? ai cung cấp máy móc công nghệ cho họ. Vẫn là việc tham dự hội chợ, nhưng 'ý đồ' của Minh Long I rất khác. [Kỷ luật về tư duy vượt ra ngoài khuôn khổ.]

Thành công đến sau 15 năm dự hội chợ khẳng định: lao động sáng tạo muốn có thành tựu phải thực thi có kỷ luật.

Quyết đoán trong ĐMST nhưng Minh Long I không mạo hiểm. Một phương pháp lao động sáng tạo đã được ông Lý Ngọc Minh phát triển và rèn luyện trong nhiều năm. Quan trọng hơn, đây là năm nguyên tắc kỷ luật mà mọi thành viên của Minh Long I đều phải nắm bắt và thực hành:

1. Đơn giản và hiệu quả

2. An toàn hai lần (cân nhắc thấu đáo, nghĩ dọc và nghĩ ngang)

3. Làm cho bằng được

4. Vui vẻ và cởi mở

5. Chân tình và thực lòng

\section{Sức bật của ĐMST}

Tinh thần khởi nghiệp là động lực quan trọng nhất làm nên thành tựu tăng trưởng của nền kinh tế Việt Nam trong giai đoạn đổi mới (Vuong: 2007[8] và Vuong et.al.: 2011[9]). Tuy vậy, quá trình phát triển kinh tế mới chỉ giải phóng lực lượng lao động và hoạt động kinh tế thị trường - những yếu tố mang lại động lực thương mại cho lực lượng khởi nghiệp trong nổ lực hoạt động hiệu quả hơn. Để có năng lực cạnh tranh mạnh mẽ, tại các doanh nghiệp cần có ĐSMT đáng kể trong thái độ và cả phương pháp kinh doanh.

Năng lực sáng tạo và đổi mới quan trọng hơn rất nhiều các yếu tố đầu vào vẫn luôn được công nhận có vai trò quyết định trong khuôn khổ học thuyết kinh tế của $D$. Ricardo, như đất đai, vốn hay lao động. Với Ricardo, nhiều đầu vào sẽ cho nhiều đầu ra. Thực tiễn kinh tế Việt Nam những năm vừa qua có quá nhiều phản ví dụ cho quan điểm kinh tế Ricardo.

Trong tác phẩm kinh điển The Wealth of Nations (1776), A. Smith nhận định rằng khai thác các cơ hội ở hiện tại hay dự kiến sẽ xuất hiện trong tương lai - cùng với động lực tự thân tìm kiếm các lợi ích kinh tế sẽ dẫn tới các hoạt động kinh tế chủ động tự lập, dám chấp nhận thách thức và mang tính thương mại cao. Tất cả các yếu tố này kết hợp cùng nhau tạo thành tinh thần khởi nghiệp trong xã hội.

Vương et al. (2013) khảo sát quan hệ văn hóa-sáng tạo-khởi nghiệp từ 115 trường hợp thành công kinh doanh tại Việt Nam, tập hợp qua thông tin trên các báo, tạp chí kinh doanh và quan sát trong thực tiễn làm việc với các doanh nghiệp.[10] Phân tích thống kê quan hệ giữa ba giá trị văn hóa - (i) kinh doanh dựa vào quan hệ cá nhân, (ii) chấp nhận bất trắc và (iii) khả nắng huy động đủ nguồn lực - và ba cách thức sáng tạo của doanh nghiệp - (i) đưa ra sản phẩm mới sau một quá trình tìm kiếm các ý tưởng mới, hoàn thiện năng lực chuyên môn và kiên trì thực hiện, (ii) nhận thức bất ngờ về giải pháp với vấn đề hoặc thực sự hiểu thấu ý tưởng, và (iii) ý tưởng đột phá mà phần lớn không hề giống bất kỳ sự hình dung nào trước khi bắt tay vào giải quyết vấn đề - đưa tới kết luận: Trong giai đoạn khởi nghiệp, giá trị văn hóa và phương thức sáng tạo là những nhân tố có ảnh hưởng đáng kể tới thành công kinh doanh. 
Những ảnh hưởng này giảm đii, thậm chí không mấy rõ ràng, khi doanh nghiệp đã phát triển bề thế.

\section{Độ lệch i2Metrix giữa số đo bình quân và số đo doanh nghiệp tụ̣ đánh giá}

Trong quá trình khảo sát năng lực ĐMST tại 19 doanh nghiệp, nhóm nghiên cứu i2Metrix phải luôn rất nỗ lực gạt bỏ cảm xúc, đảm bảo tính khách quan cao nhất cho mỗi điểm đánh giá. Bởi lẽ, cả 19 doanh nghiệp đều là những thương hiệu uy tín, có bề dầy thành công trên thị trường, từng thành tựu ĐMST đều là những câu chuyện hấp dẫn và ấn tượng.

Thế nhưng, người cho điểm nghiêm khắc hơn cả lại chính là các vị đại diện doanh nghiệp. Trên $60 \%$ doanh nghiệp được khảo sát có độ đo i2Metrix tự đánh giá thấp hơn độ đo bình quân. Tín hiệu này cho thấy dù đã đạt tới quy mô sản xuất lớn, có thành tựu kinh doanh ấn tượng, tinh thần khởi nghiệp trong nhóm doanh nghiệp khảo sát vẫn tiếp tục được nuôi dưỡng và hun đúc. Sự thỏa mãn, tự bằng lòng, ước muốn nghỉ ngơi không hề xuất hiện.

Vừa chia sẻ niềm vui về đợt thành tích bán hàng trong dịp Lễ Tình nhân (14-2) có doanh số vượt kế hoạch tới gần $30 \%$, nữ lãnh đạo doanh nghiệp vừa mổ xẻ ngay những điểm chưa hài lòng do phối hợp chưa nhuần nhuyễn giữa các bộ phận. Không chỉ có vậy, chị cũng cho biết thêm, buổi tổng kết đợt Tuần lễ Valentine sẽ phải có nội dung quan trọng là điều chỉnh kế hoạch bán hàng cho ngày Quốc tế Phụ nữ (8-3) ra sao để không những không lặp lại sai sót mà còn phải bán tốt hơn.

Tinh thần luôn hướng về phía trước và thái độ săn sàng đối diện với bất trắc trên thương trường bằng chính năng lực ĐMST của doanh nghiệp là những chỉ báo gia tăng độ tin cậy cho mọi dự báo về thành công kinh doanh trong tương lai.

\section{Chú thích:}

[1]Vuong, Q.H., \& Napier, N.K. (2012). Coffee Filters and Creativity: The Value of Multiple Filters in the Creative Process. Working Papers CEB No. 12-036, ULB - Université Libre de Bruxelles.

[2] Mike Maddock (2013). "Invention: The Entrepreneurial Curse," Forbes, 15-5.

[3] DHVP Research (2013). "Đổi mới có thực sự cần thiết?," DHVP Ecopolitik, Vol.2, No.1, pp.22-23, 24-7.

[4] —Vuong, Q.H. \& Napier, N.K. (2013). Acculturation and Global Mindsponge. Working Papers CEB 13-053, ULB - Universite Libre de Bruxelles.

[5] Napier, N.K. \& Nilsson, M. (2008). The Creative Discipline: Mastering the art and science of innovation. Westport: Praeger.

[6] Christensen, C.M. \& Overdorf, M. (2000). Meeting the Challenge of Disruptive Change. Harvard Business Review, March-April.

[7] MacDonald, R.W. (2008). Beat the System: 11 Secrets to Building an Entrepreneurial Culture in a Bureaucratic World, John Wiley \& Sons, Inc.

[8] Vuong, Q.H. (2007). Văn Minh Làm Giàu \& Nguồn Gốc Của Cải. Hà Nội: NXB Chính Trị Quốc Gia Sự Thật.

[9] Vuong, Q.H., Dam, V.N., Van Houtte D. \& Tran T.D. (2011). The entrepreneurial facets as precursor to Vietnam's economic renovation in 1986. The IUP Journal of Entrepreneurship Development, 8(4).

[10] Vuong, Q.H., Napier, N.K., and Tran, T.D. (2013). A Categorical Data Analysis on Relationships between Culture, Creativity and Business Stage: The Case of Vietnam. International Journal of Transitions and Innovation Systems, 3(1): 4-24.

[11] Gupta, A. K. \& Govindarajan, V. (2002). Cultivating a global mindset. Academy of Management Executive, 16(1), 116-126.

(c) Copyright 2014 - VietBuzz.org

Từ điển: $\mathbf{A}|\mathrm{B}| \mathrm{C}|\mathrm{D}| \mathrm{E}|\mathrm{F}| \mathbf{G}|\mathbf{H}| \mathbf{I}|\mathrm{J}| \mathrm{K}|\mathrm{L}| \mathrm{M}|\mathbf{N}|$

$O|P| Q|R| S|T| U|V| W|X| Y|Z|$ 


\section{References}

[1] Vuong, Q. H., \& Napier, N. K. (2014). Making creativity: the value of multiple filters in the innovation process. International Journal of Transitions and Innovation Systems, 3(4), 294-327.

[2] Maddock, M. (2013). Invention: The Entrepreneurial Curse. Forbes, 15-5.

[3] DHVP Research (2013). Đổi mới có thực sự cần thiết?. DHVP Ecopolitik, 2(1), 22-23.

[4] Vuong, Q. H., \& Napier, N. K. (2015). Acculturation and global mindsponge: an emerging market perspective. International Journal of Intercultural Relations, 49, 354-367.

[5] Napier, N.K., \& Nilsson, M. (2008). The Creative Discipline: Mastering the art and science of innovation. Westport: Praeger.

[6] Christensen, C. M., \& Overdorf, M. (2000). Meeting the Challenge of Disruptive Change. Harvard Business Review, March-April.

[7] MacDonald, R. W. (2008). Beat the System: 11 Secrets to Building an Entrepreneurial Culture in a Bureaucratic World, John Wiley \& Sons, Inc.

[8] Vuong, Q. H. (2007). Văn Minh Làm Giàu \& Nguồn Gốc Của Cải. Hà Nội: NXB Chính Trị Quốc Gia - Sự Thật.

[9] Vuong, Q. H., Dam, V. N., Van Houtte D., \& Tran T.D. (2011). The entrepreneurial facets as precursor to Vietnam's economic renovation in 1986. The IUP Journal of Entrepreneurship Development, 8(4), 6-47.

[10] Vuong, Q. H., Napier, N. K., \& Tran, T. D. (2013). A Categorical Data Analysis on Relationships between Culture, Creativity and Business Stage: The Case of Vietnam. International Journal of Transitions and Innovation Systems, 3(1): 4-24.

[11] Gupta, A. K., \& Govindarajan, V. (2002). Cultivating a global mindset. Academy of Management Executive, 16(1), 116-126. 